\title{
University Pathways of Graduate Students: Professionalization, Innovation and Identity. A French-Argentine Comparative Study
}

\author{
Miriam Aparicio \\ CONICET (National Council for Scientific and Technical Research, Parque General San Martin, Mendoza, Argentina) - \\ Argentina. Lead Researcher. \\ National University of Cuyo
}

\begin{abstract}
This article presents findings from two studies carried out with fourth level university students in Argentina, namely Argentine PhDs working at UNCuyo, and with a second group made up of PhDs who are taking part in Professionalization programs (Programs of International Cooperation) in France. This is a comparative study. It is thought that after showing a certain level of excellence and being in contact with other cultures, differences between the groups may exist in terms of perspectives for future work, the role of innovation and competencies to be developed. Various hypotheses were considered. Both studies included common variables related to issues that affect, on the one hand, the effectivity and quality of the University as it relates to the working world and, on the other hand, personal and professional pathways. We focused on Professionalization, Identity and Innovation, variables that involve individuals and contexts interacting with one another. The methodology was quanti-qualitative. Techniques used were semi-structured surveys, interviews and focus groups. The findings show convergences, divergences and silences in the different groups with respect to Innovation, both in its conception and roots and with respect to the future world of work (effects). The findings renew interest in education and employment policies in the face of the demands and changes that the future workplace will require. ${ }^{1}$
\end{abstract}

Keywords: Innovation, University Pathways, Professionalization, Identity

\section{Introduction}

\section{1. Theoretical Framework}

This article, derived from two complementary research projects, takes up the question of the innovation and competencies needed to be developed looking towards the workplace of the future for two groups of PhDs, groups particularly linked to innovation. The first group carries out its work at the National University of Cuyo (Mendoza, Argentina, henceforth PICTO, $\mathrm{UNCuyo}^{2}$ ). The second is made up of PhDs that are currently carrying out an international academic-scientific mobility program in France (henceforth IAM) under the framework of the Bilateral Cooperation Program. PhDs and graduate students from other countries also participated in the study voluntarily. This is important as being immersed in another culture already demonstrates an openness to current issues, including that of innovation, its past and its effects on the workplace of the future (Aparicio, $2016 \mathrm{~d}$ and e).

On the one hand, this issue concerns the effectiveness and quality of university institutions as they relate to the world of work, and on the other hand organizations that innovate, with the positives and negatives that this implies (Aparicio, 2005, 2010). In addition, it involves the individuals within these contexts of accelerated change that have not always been prepared by the educational system of by the workplace itself for such change.

\footnotetext{
1 PICTO Project 2016-0008. BID Loan. Argentina

2 PICTO Project 2016-0008. BID Loan. Argentina
} 
In the literature, in effect, many authors point out the positive aspects of innovation and link it to necessity. Without neglecting its risks, Gilbert $(2007,2011)$ maintains that for companies, innovation is currently a necessity, both for the restructuring of work itself and for the management of personnel. Innovation also concerns methods of communication and management. The participation of associated actors at a company brings about a new conception of organizational relationships and development. In this sense, the difficulties and obstacles or dysfunction in communication tend to have marked consequences on the ability to innovate.

Their competencies (PICTO), more or less developed, and the workplace context in which they participate will influence their opportunities for professional mobility, as well as their satisfaction (Aparicio 2014 b; 2016 a, b, c, f) and even moreso their opportunities for insertion into the working world and permanence when faced with never before seen changes. These changes will require new ways of educating in competencies and conversions and, in the subjective realm, special flexibility, openness and reflection that allows us to modify our models of thought and action, adapting ourselves to the new framework of companies (Perrenoud, 2007; OECD, 2018 a and b); Aparicio 2019).

To innovate means to change our existing social representations with respect to ideas and procedures, as described by Moscovici (1961), Argirys (1982), Shon (1992) and Gaglio (2011), among others. These modifications in our ways of thinking imply a mental restructuring in which new concepts or ways of doing things, previously rejected or unknown, become internalized, fundamentally through communication (Abric, 1996; Kridis, 2008; Aparicio, 2013). In this way they become part of our mentalities and lead to a restructuring of our conceptions, ideas, procedures and ways of doing things. From the perspective of Cognitive Psychology, in said restructuring the subsensor concepts (higher and more encompassing than others) relocate to become equal to concepts previously subsumed. For its part, Social Psychology helps us to understand how this change in world view takes place, a change "in our mental cards" that allows us to read reality and either accept its changes or not, sharing new patterns of ideas and behaviors. It allows us to understand how these "movements" of ideas are produced which enable us to see reality differently, making a significant contribution to the interpretation of change by way of the "polyphasic cognitive" mechanism. This mechanism, described by Moscovici, helps us to learn and accept new procedures after completing processes of negotiation. This sometimes implies a loss of power as what belonged to the individual now belongs to the group (Crozier, 1963; 1977).

The only certainty is that we live in a world of constant change, change which generates much uncertainty and bombards our personal and professional identities (Kaddouri, 2008; Dubar, 1991, 2000ª and 2000 b; Silva \& Aparicio, 2015; Aparicio, $2016 \mathrm{a}, \mathrm{g})$.

Regarding what concerns us here, innovation and change, what relates to identity is the lack of recognition on the part of specialists of what constitutes real innovation, something which exceeds mere novelty and is expected to have an impact on our culture (Csikzentmihalyii, 1990; 1998). This has created tensions and has caused identity to become fractured or fragile. Though we cannot go in-depth on the topic here, identity is biographical and at the same time relational: it is achieved through interaction with another and through recognition and tends to weaken over time according to the results of previous research on organizations (Aparicio 2012 a and b; 2014 c; 2015 a and b; Aparicio \& Cros, 2015 c), with a lack of recognition currently a fundamental factor for personal crises in the workplace.

We see then that the issue is complex. It involves multiple aspects that concern education (in educational and workplace institutions) and objective and subjective achievement (satisfaction and mobility, both academic and in the workplace), impacting identity (cf. papers cited; also Aparicio $2007^{\mathrm{a}}$ and b). All of these aspects involve both the organizations themselves and the individuals who are part of them (Aparicio, 2009 a. b and c; 2014 a and d).

\section{I.2. Innovation}

To start with, we must point out that while the concept of communication, just to take one case, is on its fourth generation after the work of Shannon \& Weawer (1975), the concept of innovation continues to be relatively general and ambiguous. Neither the Grand Dictionnaire de Psychologie (Larousse, 1994), nor the Dictionnaire Usuel de Psychologie (Norbert Sillamy, Bordas, 1983) nor the Vocabulaire de la Psychologie de Henri Pieron (PUF, 1963) give a clear presentation of the concept of innovation. One must turn to the Vocabulaire Technique et Critique de la Philosophie (PUF: 1972) by André Lalande to find a definition of innovation as "the production of something new, making reference to the concept of imagination (p. 516)". and continues "but this definition is quite general." On the other hand, the Le Grand Dictionnaire de Psychologie provides an entry for the concept of creativity defined as the ability to produce new works and new behaviors 
and to have new solutions to a problem" (p. 181, cit by Kridis, 2008: 5). In this line of thought, innovation is consequently related to creativity. But this is just one of many aspects linked to the phenomenon (Csikzentmihalyii, 1998, op cit). In this author's opinion, from her systemic theory sui generis (Aparicio $2015 \mathrm{a}$ and b, fundamentally), this is still a very linear concept in which innovation is seen as an effect of creativity. This is in part true. However, both innovation and creativity are complex and interactive phenomena and can only be understood within the triple system of society, culture and personality (Aparicio, 2011 e, f; 2012 a). Because of this complexity, it is difficult to create one single definition of either innovation or creativity which encompasses all of their components. For this reason, it is our intention to:

-observe several marked aspects of innovation and its relationship to creativity. For all cases, we will highlight central ideas of the founding fathers of the topic.

-to analyze which disciplinary contexts have addressed innovation over the last few decades.

We must point out that these aspects are intertwined. When noting the link between innovation and Cognitive Sciences, the authors will highlight some of these characteristics from their conception and discipline.

\section{I.2.1. Innovation and related notions: convergences and divergences}

With respect to the fundamental aspects that define innovation, it is important to remember that it is a process with various dimensions (Kridis, 2008: 10). Our description of these aspects, though brief, will lead us to our second area of interest: its relationship with other disciplines.

The following are several important aspects that will allow us to avoid confusion.

*An innovation is not a novelty: many novelties never became innovations due to the fact that they had no cultural imprint or received no recognition by experts of their time and place (Kridis, 2008: 30); also Csikzentmihalyi, 1998, Chapters cits).

\section{*Is an innovation a discovery/invention?}

Malinvaud (1986) defines a discovery as "... what has been both taken and perceived as involving important and sudden growth of knowledge, and which can be introduced until it seems irreversible (Masmoudi, 2008: 31; Gilbert \& Chiapello, 2013). If we look at the effects of the discovery, it must have a certain degree of generality and real meaningful reach. It mustn't concern only one object or only one event. It must be important enough to be incorporated into a scientific corpus. Examples are Galileo in Astronomy and Fleming or Pasteur in Biology.

According to Masmoudi, many factors come into play. In its conception, related more to what innovation represents on the science spectrum, it combines elements of a process (the effects of the discovery in the scientific corpus that exceed the impact or change in one subject or object). Nevertheless, it also makes reference to psychosocial characteristics of the subject such as experimental rigor and perseverance, as well as opportunity and indetermination. Hence, we can say that discovery is an observable and irrefutable fact, contributing something "new" to science, closely linked to a specific moment in time.

With respect to invention, we point out that "... if discovery takes place in natural sciences and in formal sciences, invention takes place in the realm of techniques. It is, in effect, a specific and effective result of consistent work on a physical production, and defined as such due to its utility and newness. Invention is one of the products of innovation (cf. Masmoudi, op cit., p 31).

For his part, Gaglio notes the dissociation that exists between innovation and invention. The latter represents something new, the creation of a technical or organizational novelty related to goods, services and devices. Innovation, on the other hand, represents the social and economic process that leads to the invention finally being used or not. Invention is only potential, an element ready to use; innovation is effective incorporation into a social context. They are not exclusive and do overlap but moving from one to the other is not automatic.

\section{${ }^{*}$ Is innovation related to creativity?}

In the literature, innovation is linked to creativity (Csikzentmihalyi, 1988, 1998); a creativity that is not to be seen as something brilliant or genius coming from one individual but rather to be seen as the necessary interaction of an individual with his context. It is this context (or realm for Csikzentmihalyi) and its experts that will determine if what has been proposed 
constitutes real innovation, if it leaves a mark on the culture and is not just a mere novelty (Popper, 1984, UNESCO, 1982), in short, if it has the recognition it needs to be implemented (Csikzentmihalyi, Chapter 2 and Chapter 14). Dubar (2000 ${ }^{\mathrm{a}}$ and $2000 \mathrm{~b}$ ), without referring to creativity as Csikzentmihalyi does, presents another angle of this recognition: the opportunity to establish a personal/professional identity among others (Aparicio, $2012 \mathrm{a} ; 2015 \mathrm{a}$ and b).

Despite being related concepts, it is necessary to distinguish creativity from innovation. Gaglio (2011) affirms that creativity is "an inseparable component of the process of innovation", an "ability" that allows us to encourage the growth of novelty. Without talent, ingenuity or curiosity, he says, neither chance nor necessity will generate innovation. Nevertheless, creativity must not be confused with innovation, nor must it be subsumed to the process that this entails. Callon et al (2006) maintain that every innovation has, necessarily, a "founding father". In addition, creativity is expressed in the process of innovation and not only during its beginnings. Therefore, grouping innovation and creativity would be to join the process of innovation with its beginnings.

\section{*Innovation as a process}

Various authors and disciplines have identified this aspect as being central.

Gaglio (2011), from the discipline of Sociology, defines innovation as something new, the fruits of a process linked to generally positive representations, contrary to what happened in the Middle Ages. It is "an ideal to reach, we must innovate and be innovative". It is associated with progress, the future, creativity, technologies, and improvements in daily life and benefits. In the field of economics it represents both a risk and an opportunity; it is a "Sword of Damocles". Frequently we hear that a business that does not innovate, dies. Joseph A. Schumpeter (1942), in his writings from almost a century ago, points out this ambivalence when he says that innovation is fundamentally "creative destruction" that transforms and creates something new while at the same time demolishing the old. Sociologically, innovation is considered neither good nor bad. There are winners and losers. What is certain is that today innovation permeates all fields, worrying politicians, researchers, psychologists and business owners. We must manage innovation and establish methods for stimulating creativity.

For his part, Kridis says that "innovation is defined as ... a process as it necessarily supposes a set of stages that lead to the production of innovations. These innovations are characterized as being useful for both individuals and groups" (2008: p. 31).

\section{*Innovation as a four-dimensional process}

The following dimensions indirectly address the epistemological aspect and bring us closer to a systemic position: integrative temporal, nonlinear relational, productive transformational acting upon products and resources and cooperativecollaborative.

An analysis of these dimensions leads us to address innovation from other fields.

\section{I.2.2. Innovation and its relationship with disciplinary fields}

\section{a) Cognitive Sciences}

Innovation goes from Cognitive Psychology to Cognitive Sciences (Neuroscience, Artificial Intelligence, Cybernetics) with Eiser, 1967. It is important to note that Eiser applies the innovative aspect to the birth of the discipline itself from an emerging perspective of integration, highlighting the integration of theoretical and methodological contributions from different approaches and schools of thought that reject reductionism and the one-dimensional (Aparicio, 2005, 2007 a and b, 2009, 2015; 2019).

As can be seen, Cognition Sciences lean towards an interdisciplinary perspective and transdisciplinarity, bringing together Mathematics (a hard science) and Psychology (a soft science) (Aparicio 2010).

With respect to the "productive transformational, of processes and resources" dimension, it is important to note that innovation implies a change in our "cognitive cards" (cognitive cartography). Here, Cognitive Psychology joins Social Psychology (Moscovici, 1961). It entails the creation of value, the transformation of an idea and service or application in response to a need and it integrates activities that involve a level of future investment, generating economic, physical and cognitive spending while utilizing resources available in the form of technical data and scientific laws. 
In other words, all cognitive systems transform stimuli into representations thanks to processes and then transform these representations into data needed for acting and decision-making ("memes" or units of information Csikzentmihalyi's conception, 1998).

As regards the "cooperative" dimension, every process of innovation requires actors that come from diverse walks of life, sometimes from fields with projects that are located on disciplinary borders and which combine efforts, heading towards interdisciplinarity and transdisciplinarity (Aparicio, 2010).

Continuing with the Cognitive Sciences and associating them with Informatics, Communication and Information Theory (IT), we point out that Cybernetics has also made important contributions, contributions which go beyond the scope of the objectives of this paper (Donnadieu, 2008: 49-73). But we do want to mention two contributions concerning innovation from a systemic and interactive perspective: the notions of complex retroaction and interaction. However even these were insufficient. Information Theory, observing its limits and positivist and reductionist perspective, was completed with Systemics (Palo Alto School (1960-70). This group proposes another model, based on a jazz orchestra, in which musicians are moved by the euphoria of improvisation. With the metaphor of the cultural orchestra, there is no conductor or sheet music. Each individual plays in agreement with the others (Donnadieu, op. cit, p. 55). In this model, emphasis is placed not on the actors or on the message communicated, but rather on the system as a whole as an inseparable network of relationships (principle of systemic globality). When man is born, he enters a network of relationships woven by the socioculture in which "non-behavior" does not exist. Even silence, or a schizophrenic in a catatonic state, is a message (Bateson et al, 1956). As such, as P. Watzlawick states, we cannot not communicate.

Communication Theory, therefore, receives a double inheritance, from the influence of Watzlawick (1980) and that of Bateson (1984) (symbolic exchange). In the marketplace, the buyer pays the vendor with a unique currency. It is instantaneous and symmetric: Homo aeconomicus. However, in symbolic exchange, one must know oneself and make oneself known as a donator (Mauss, 1950). We see, then, that the need for recognition emerges quite early on.

Regarding the link between communication and innovation, Kridis maintains that "the ability to construct and innovate occurs within a relatively broad theoretical field, however, it follows a common thread: innovative processes depend on contexts favorable to communication" (2008: 6).

Informatics (at the historical and theoretical-methodological level) has also been a vector of innovation for Cognitive Sciences. To close, a current and relevant point of common interest between these sciences and innovation is the project started in 2005: The Brain and Cognitive Sciences Project MIT.

b) Social Psychology: its existence as a discipline as regards innovation is indisputable. Everything is made up of social representations that impact identity -our focus in the study on innovation- and we must always do something external to ourselves: "we must make ourselves known as donators".

This is just one part of the relationship between Cognition Sciences, Systemic Theory of Communication and Social Psychology.

Social Psychology has also defined innovation as a process of social influence, with the source generally being the minority or individual who strives to introduce or create new ideas or new ways of thinking and behaving, modifying ideas received, traditional attitudes and antiquated ways of thinking and behaving. The relationship with communication is once again present.

c) Communication Sciences: let us focus for a moment on communication and innovation, without forgetting about creativity.

Innovation, as we have said, is the art of channeling new ideas to create new products or to offer new services. Innovation is a guarantee of creativity. Creativity can thus be represented by the climbing up of a ladder while innovation is the descent. The creative process gets underway and becomes tangible action, leading to change. Change implies a creative process, followed by innovation.

But it is also necessary to remember that creativity and innovation require a flexibility that can be defined as the ability to react to and anticipate sometimes unpredictable events (Bandura, 1977; McClelland, 1961), an ability that both individuals 
and the system possesses. Once again, innovation is linked to the Psychology of Innovation, Social Psychology and Cognitive Psychology.

Communication plays an important role. In effect, creativity consists of efficient activation and communication of projects, whether we are aware of the restructuring of the perceived order or not. The act of creating consists of combining dimensions of experience until we form a whole made up of more than what existed at the starting point. In other words, there exist elements or information to combine.

In terms of innovation, it also entails information. In the case of businesses, this information may come from either inside or outside of the organization. A business is an open system in which all elements interact. It must be capable of selfregulation and of learning how to learn in order to adapt itself to a changing environment. It must be able to reactivate to ensure its survival. In an organization, communication becomes an intermediary variable. Participative management is fundamental as it favors communication.

From the epistemological and disciplinary point of view, there are several different methodologies of observation of this phenomenon, some linear and particular and others absolutely systemic, understood only within a process of interaction between the individual (he who creates) and the context that adopts him as something original or new, though based on something previous, and which entails the combination of preexisting elements ("memes" or symbolic units of communication) (Csikzentmihalyi, 1988, 1998; Aparicio (1977, 2005, 2007 a and b, 2015 a and b).

At this epistemological level, the opportunity to innovate is directly linked with the causal opening to the world, that is, to the possibility of leaving an imprint. An imprint is not a closing off, it means that it is always possible to influence and act upon the world (Popper, 1984). We also cannot neglect conception, the cognitive exercise of "investigation" of that which does not exist but which has "le designo" according to Leonardo da Vinci, the "ingenium".

From Communication and Cognitive Sciences, Masmoudi (2008) also adopts a systemic perspective regarding innovation, considering these sciences as innovation as they imply the unification of different approaches. This unification requires an integration of concepts and perspectives, relating models, theories and disciplines, and a rich collaboration among researchers from different fields. It is the fruit of a process of evolutionary innovation in perpetual restructuring.

In sum, innovation is a reality and a concept which appears in discourse referring to the panacea, as a reality that imposes itself, that allows businesses and nations to survive and compete. At other times, it refers to a "demonizing" question that situates us in a vacuum of unpredictable consequences in the short term.

In effect, change intimidates us. New types of organization (lean-management, flex-office, agilité, etc.), new technologies (digital/technological revolution) and new workplace and employment conditions invade our society, sometimes brutally, in ways for which we are not prepared.

For its part, the education system does not always maintain its curricula up-to-date (Berlinger, 2017). Nor does the role of change and innovation occupy a privileged place in communication, perhaps in order not to create a sense of "panic".

This issue also concerns university students. Do our universities' programs of study change as quickly as new workplace requirements? How many institutions educate non-programmers on programming and robotics? How many encourage creativity? How many dare to break with the traditional models and consolidate competencies that we know will be essential in the future? (Aparicio, 2019, Rapport OECD, PISA, op. cits) How many universities have implemented reforms at the base-level, not just of structure, after reviewing research results? (Aparicio, 2005, 2009; 2007 a and b; other articles cited there since 1997).

Faced with this complex reality, we must ask ourselves various questions. How do our PhDs perceive the situation? How clear is their concept of innovation? How do they perceive the concept as it relates to the future of the workplace or the workplace of the future? Are there differences according to disciplinary field?

\section{Methodology}

Quantitative and qualitative.

1. Sample: Our comparative research sample was made up of two groups: the first from UNCuyo's PICTO Program (data collected in Mendoza, Argentina) and the second being graduate level students (from Master's or PhD programs) 
completing academic exchanges in Paris, Frances (international academic mobility or IAM). We must point out that this is not a representative sample as all responses were voluntary.

Group 1, PICTO: we worked with three groups at UNCuyo:

a) UNCuyo professors from four of its school (Exact and Natural Sciences, Agrarian and Engineering, Philosophy and Letters and Economics). This is a comparative study whose objective was to detect central issues to each academic unit through the representations of different actors.

b) Academic support personnel at different levels. We attempted to have representation from all ranks.

c) CONICET PhDs or scientists working as professors at the UNCuyo.

Group 2, IAM: In Paris, we interviewed $20 \%$ of individuals housed at the Argentine Residence on the International Campus, as well as groups of foreigners participating in exchanges. From this, we were able to obtain additional vision and perspective, influenced both by education and by the contextual situation.

2. Techniques: interviews were used for both groups. Afterward, a semi-structured survey was administered which included common key themes in order to be subsequently able to make comparisons.

For the IAM group, data was collected on three opportunities. We also worked with focus groups, though fewer individuals participated than those who responded to the survey. Many both work and study and for this reason it was difficult to gather.

The model included base, socio-cultural, pedagogical-institutional and structural variables/indicators for both groups, with the base issue being that which affects university education (undergraduate and graduate) as it relates to the current workplace demands.

We also included items related to other issues which currently impact and will continue to impact the work of the future and which are linked to education and contextual opportunities. Our research took into account variables such as innovation, creativity, the impact of both on the future marketplace, risks and benefits according to disciplinary fields and social levels and factors related to satisfaction (differentiated according to disciplinary field).

The semi-structured survey included open-ended phrases in order that we could truly hear actors' voices. This allowed us to apply the hierarchical evocation technique, central to qualitative studies (Abric, 2001). With this instrument, we are able to identify the words most used by individuals and those most important for a certain variable, in this case, innovation.

In the P2 quadrant (nucleus of the representation) are located the most frequent and most important categories; in the P3 quadrant, those most frequent but least important; in the P4 quadrant, those which are overall least important; and finally, in the P1 quadrant (low frequency and high importance), appear the so-called elements of contrast or innovators that show group differences. Through the use of this technique, we were able to understand the most notable convergences and divergences.

Figure 1. The Quadrants (The hierarchical evocation technique).

\begin{tabular}{|l|l|}
\hline P1 & P2 \\
\hline P4 & P3 \\
\hline
\end{tabular}

\section{Guiding questions / Hypotheses}

Firstly, we decided to compare the opinions of PhDs working in Argentina with those of university-educated individuals (PhDs/Masters or highly trained professionals) who had completed an experience of international cooperation. We expected to find differences in responses due to one group's insertion in another culture.

Our general questions / hypotheses were:

\section{*PICTO and IAM}

1- There will exist a different perspective between the groups of PhDs working locally and those who, for a combination of factors (personal, motivational, family, institutional, geographical), decide to complete academic exchanges in Europe. 
On the one hand, it is important to note that there are very few quanti-qualitative studies that address the conditioning factors that lead to mobility. On the other hand, there are very few longitudinal studies that demonstrate the impact that such mobility has on an individual. This was one of our intentions.

*Only IAM: We were interested to know which lines of R\&D these individuals hoped to consolidate upon returning to the country and why they had selected those particular study centers abroad. Did inter-institutional agreements play a role or insertion into companies that seek to educate their personnel abroad?

\section{*Observing the two groups (PICTO and IAM):}

2- How much clarity was there in both groups with respect to what innovation implies? How many were aware that all innovation supposes innovators but also an adopting context? These questions seem naïve but the answers given left us perplexed.

3- What abilities / competencies do they associate with innovation? Are they different according to disciplinary field? Does the need for transdisciplinarity emerge?

4-What role does creativity play in innovation?

5 - How do they imagine the future of work, mediated by robotization and global automatization? Which professions would experience the most change?

6- How do they see innovation with respect to future work? Are they aware of its positive and/or negative aspects? Its risks and potential? Its necessity or lack thereof?

7- Do they associate innovation with education? Are some fields priorities where innovation is currently crystallized? What do they think about the development of the educational system as regards what the workplace now requires in our country and in others? Is it appropriate?

8- What competencies do they link to innovation? All of this concerns professionalization, which impacts pathways and identity.

9- At an epistemological-methodological level: Do they see innovation as being more associated with linear deterministic processes, with processes or with a system of interactions?

10- Which aspects mentioned in the international literature do our professionals reference most?

From our analysis of responses given by Argentine professionals working in Argentina and in France, we are able to respond to questions concerning the definition of innovation, highlighting which aspects emerge from representations shared by both groups. We also note the silences that demonstrate a certain uncertainty or ignorance. Said representations have their correlations in practice. If they cannot be perceived in all of their complexity, what can be expected at the level of change and practice? ${ }^{1}$

\section{The nucleus of the representation of innovation in light of representations observed (specific technique of hierarchical evocation)}

After reading all individual responses for the IAM group, four categories were inferred:

$<<$ Change that entails cognitive-procedural competencies >

$<<$ Changes that entails application and demanders $>>$

$<<$ Change that looks to the future, to competitiveness and to political repositioning >>

$<<$ Education at the base-level according to disciplines and contexts for transformation>>

\footnotetext{
${ }^{1}$ Responses to the rest of the questions will be given in subsequent articles (in preparation).
} 
From the combination of the criteria frequency and importance of the representations shared by $\mathrm{PhDs}$, four quadrants emerged, mentioned above (see Techniques). The P2 quadrant constitutes the nucleus of the representation.

\section{Development}

Following this article's logic, we will present our findings taking into account the responses of both groups (PICTO and IAM). We will mention both the convergences and the silences, which also "speak" and "communicate".

Of all the questions proposed with respect to innovation, here we will focus on:

i- Salient aspects of the definition: need for a demander; likewise, absent characteristics emerge which are decisive for defining something like innovation.

ii- Convergences found with respect to the salient character of innovation in the international literature; that is, that it is adopted and recognized by one's peers at a particular moment and place and that it is recognized as something (idea, concept, product) that impacts the culture (Csikzentmihalyi, 1988, 1998). We observe how many respondents made reference to the interaction between individual and context in the definition and how many referred to the cultural aspect. In other words, how many allude to the triad of Society/Culture/Personality associated with innovation.

We now continue with the analysis, going back to the categories found and their positioning in the four quadrants.

\section{Item i- Salient aspects of the definition of innovation}

Here we observe the need for a demander.

IAM: We begin with words used by individuals participating in an international academic mobility experience as regards the category "Change that implies implementation with demanders". The responses were the following:

Change that entails application and demanders / change that improves something / to find new solutions to old problems / utility: with more intention than creativity / speed / transformation with application / utility: connecting things that exist so that they become more useful / creating something to be applied / transference.

We observed that the need for application and the existence of demanders were essential in the case of two foreigners (from Germany); another two foreigners also mention this aspect; finally, four Argentines in the IAM group make a more indirect reference to this aspect, with a graduate student in Philosophy clearly stating: "transformation with application".

We will now see the terms evoked in relation to innovation, already included in the four categories and quadrants for the IAM group.

If we observe Category 1 (associated with the demander), it does not appear in the nucleus but rather in the last and least significant of the peripheries (P4).

P2: Nucleus of the representation (high frequency, high importance; henceforth $\mathrm{F}$ for frequency and I for importance). Here are found the following categories:

$<<$ Change that entails cognitive-procedural strategies >> (High F, 32.6\%; High I, 36\%).

<<Change looking towards the future, competitiveness and political repositioning > (High F, 25\%; High I, 25\%).

P4: This quadrant is the least representative as it joins what was least recurrent and least relevant for the group. It is precisely here where the category that defines innovation (application and demanders) together with another category can be found:

<<Change that entails application and demanders >> (Low F, 8, 7\%; Low I, 10\%).

$<<$ Education at the base-level according to disciplines and contexts for transformation»> (Low F, 5, 4\%; Low I, 7\%).

Noteworthy observations: 


\section{A. IAM}

1. With respect to Category 1 (utility/demander): the fact that a defining element for an innovation to exist is that there must be a demander to implement it appears in quadrant P4 (low frequency: $8.7 \%$, low importance: $2 \%$ ). That is, it is not a central aspect, a fact which demonstrates a certain level of ignorance regarding what defines innovation. In absolute terms, only two professionals made any explicit mention of this.

1.a- It is also interesting to note that this aspect of "applicability" and "utility" appears in all of the responses from foreigners in France. On the other hand, "utility" is an aspect that is only secondary for the Argentines. This could be reflecting the traditional deep-rooted divorce between theory and practice; between academia and the productive and technological sector.

1.b- Only one professional observed that innovation was not something continual, but rather a spiral movement: "it implies creating in order to create again (non-continual)".

1.c- Only one professional saw innovation with a linear positive sense: "a change that improves something".

1.d- One connected it with creativity: "utility: more intentional than creativity". The perspective of the Germans who participated was clear in this sense, approximating the central element without which there is no innovation.

1.e- One Master's student understood it indirectly as a process: "utility: connecting things that exist to make them more useful". That is, she understood that innovation does not come out of nowhere, but rather always requires something previous. In this sense, it coincides with creativity (Csikzentmihalyi, 1998).

1.f- It is important to note that in this category for the IAM group, responses from four graduates of the hard sciences and five graduates from the soft sciences were included, however, only two Germans make express reference to "utility", one from the hard sciences and one from the soft sciences. Does context have an impact, with the German context being more pragmatic than the French or Argentine context?

1.g- The word change was used two times.

\section{B. PICTO}

If we observe Category 1 "Application with impact", just as for the IAM group, it continues to be located in the quadrant of least importance (P4) when in reality it is the central aspect or element that defines innovation.

P2: Nucleus of the representation (high frequency, high importance). Only one category located here:

<<Change, improvement, progress (including technology, with funds) >> (High frequency, 36, 8\%; High importance, 39\%).

Here we will not dwell on the words evoked because this exceeds our objective. However, it is important to point out that in the case of PhDs at UNCuyo-PICTO, there appears repeatedly a reference to the economic aspect, to the absence of material resources that favor innovation. This was highlighted in the category with the term "funds".

The rest of the categories are located in quadrant P4 (low frequency, low importance):

<<Application with impact>> (Low F, 18, 3\%; Low I, 20\%).

$<<$ Change that entails cognitive-procedural competencies (including creativity) $>>($ Low F, 20, 2\%; Low I, 20\%).

《 Education at the base-level according to disciplines and contexts for transformation 》> (Low F, $87 \%$; Low I, 7\%).

As regards the category related to competencies, for the PICTO-UNCuyo group we included the word "creativity" as it appears several times, to such a point that some individuals confuse creativity with innovation. This implies a lack of knowledge of insufficient causes/conditions and effects. It also means being unaware of the "Time" and "Space" aspect that we have mentioned previously, that is, a before (that basically entails units of known information that can be combined) and an after. It is only then that innovation can be accepted as such by the context and valued for its cultural impact, at least for a time.

The presence of a demander, without which innovation could not exist, does not emerge practically. 
The words evoked by PhDs at UNCuyo (PICTO) in relation to the <<Application with impact > category are the following:

Hard sciences: (total $=15)$ extension / added value / relevance / experimentation / application / impact / applying new paradigms / problems / specific solutions / application of advanced science / applicability / pragmatism

Soft sciences: (total $=10$ ) going beyond with impact / real change / solving a specific problem in the same way the world is solving its problems / give a response with impact / become aware of the opportunities of the present and give them future projection (in any realm) / generate something new from something already in existence that is adopted by someone (individual or context) / create something that society is asking for and that before was not produced or was not considered a necessity

Directly speaking, "application with impact" was mentioned by three PhDs, with one stating that it is something society asks for that had never before been seen as necessary.

\section{Item ii: Recognition of the idea, concept or product by others as an aspect of cultural impact}

The idea of a need for recognition by expert peers (gatekeepers or evaluators) who determine if something is truly novel or original and if the idea, concept or product will have cultural impact did not appear in the group in France (IAM), nor did it appear in the PhDs in Mendoza (PICTO-UNCuyo).

Nevertheless, without this recognition innovation does not exist. Csikzentmihalyi (1998) is very clear in this regard, as is Gilbert (2011, 2013). Many have created novelties but they did not leave any imprint on society and have not been remembered. Recognition is therefore essential. However, as a concept it does not appear in the representations that our professionals (PICTO and IAM) have of innovation.

In view of the convergence of responses and associated factors, the cultural impact that the idea, concept or product must have to be considered an innovation is not present.

All of this means that neither group noted that innovation, linked to creativity, implies an interaction between individuals and their contexts. For the PICTO-UNCuyo group, only one PhD mentioned the word "convergence".

Globally then, we can deduce that innovation is linked to a systemic perspective.

\section{Conclusions for the Two Groups: PICTO and IAM}

-Firstly, we must point out the lack of clarity evident when identifying inherent and essential aspects of innovation.

-Secondly, the results demonstrate specific contexts for advanced university professionals, with their similarities and differences and strengths and weaknesses, which require specific responses both from organizations and from national educational and employment policy if they seek to be pertinent in order to lead to improvement and/or prevention.

-Thirdly, we observe a certain lacking in the relationship of innovation with other disciplines. Only some aspects mentioned would be associated with Social Psychology and even fewer with Cognitive Psychology. Cognition Sciences, with all of its sub-disciplines, does not appear. Nor does the Psychology of Communication.

These responses make evident holes in university education. What have we educated in? (Berlinger, 2017).

Challenges for education and employment systems are enormous. We must understand the effects of change and recover values and ethics which have been lost today.

We hope that these findings are useful to make others aware of the need to understand the different facets of innovation and of the ethics it implies; to reflect with university graduates and non-graduates alike, with business owners and government agents, in order to intervene, accompanying socio-technical transformations and favoring the personal, mesoorganizational and macro development.

\section{References}

[1] Abric, J-C. (1996). Psychologie de la communication. Paris: Colin.

[2] Abric, J-C. (2001). Prácticas sociales y representaciones. México: Coyoacán.

[3] Alter, N. (1999). La gestion du désordre en entreprise. Paris: L'Harmattan. $1^{\text {a }}$ ed. 1993. 
[4] Akrich, M.,Latour, B. \& Callon, M. (Ed.) (2006). Sociología de la traducción: textos fundadores. París: Minas Paris.

[5] Aparicio, M. (2005). Les facteurs psychosociaux en relation avec la réussite universitaire et professionnelle. $2^{\mathrm{e}}$ thèse de doctorat. Paris: Université René Descartes, Sorbonne.

[6] Aparicio, M. (2007 a). Les facteurs psychosociaux à la base de la réussite universitaire et professionnelle : aspects psychologiques et organisationne/s. HDR en Psychologie. Lille: Université de Lille3.

[7] Aparicio, M. (2007b). Mobilité et réussite universitaires et professionnelles. Du niveau macro au niveau micro. HDR en Sciences de l'éducation. Paris: Université Paris X, Nanterre.

[8] Aparicio, M. (2009 a). Les facteurs psychosociaux et la réussite universitaire et professionnelle. Université de Lille 3: ANRT.

[9] Aparicio, M. (2010 a). La evaluación de la Calidad del Sistema Universitario y de Empleo en su articulación ¿Hacia un paradigma sistémico transdisciplinario? Revista Iberoamericana de Educación (RIE), OEI. January 1-32.

[10] Aparicio M. (2011 a). Las competencias sociales ¿las grandes ausentes en la formación secundaria y universitaria? Congreso Internacional de la Red Iberoamericana de Investigación sobre la Calidad de la Educación Superior (RIAICES), Portugal. Du 24 au 26 février.

[11] Aparicio, M. (2011 b). Factores psicosociales y "competencias sociales" vinculados a logro académico como parámetros de la Calidad de la Universidad. Un estudio en Argentina. Congreso Internacional de la Red RIAICES, Portugal. Du 24 au 26 février.

[12] Aparicio, M. (2011 c). Professional Identity Crisis, Social Identity Crisis (Crises d'identités professionnelles, crises d'identités sociales). In Book of Abstracts $8 e$ Congrès de l'UES (Union Européenne de Systémique UES).

[13] Aparicio, M. (2011 d). Les trajectoires des étudiants, un jeu entre les sujets et leurs contextes institutionnels, In Book of Abstracts 8e Congrès de l'UES (Union Européenne de Systémique (UES), On line, Vol. 1.

[14] Aparicio, M. (2011 f). Systemics, Comprehension and Transdisciplinarity. An Analysis in Argentina. Acta Europeana Systemica, December 07th On Line issue). Vol. 1.

[15] Aparicio, M. (2012a). Trajectoires universitaires/professionnelles et identité. In J. Clénet (Ed.). Formations et professionnalisations : à l'épreuve de la complexité. Paris: L'Harmattan, 195-229.

[16] Aparicio, M. (2012b). Crise d'identité et devenir professionnel des étudiants qui sont engagés dans un doctorat en éducation /formation. Une approche comparative franco-argentine. Biennale internationale de l'éducation, Cnam, Paris. July 4-6.

[17] Aparicio, M. (2013). The Media and the Configuration of "Mental Maps": Their Relation to Institutional Homogenization among University Students and Disciplina Identities. Mediterranean Journal of Social Sciences, 118(4), 235-238.

[18] Aparicio, M. (2014 a). University Drop-Outs. A Systemic Play of Subjects, Institutions and Macro Contexts, Journal of Educational and Social Research, 4(2).

[19] Aparicio, M. (2014 b). Satisfaction, Professional Mobility and Leadership in Academic-Scientific Organizations, Journal of Health Science, 2(3), 135-145.

[20] Aparicio, M. (2014 c). Postgraduate Level and its Impact on Academic Studies and Professional Careers, Social and Job Mobility and Identity. A Study about PhD Graduates and PhD Students at UNCuyo Journal of Educational and Social Research, 4(2).

[21] Aparicio, M. (2015 a). Towards a sui generis Systemic Theory: The Three-Dimensional Spiral of Sense. A Study in Argentina Applied to Identity and Professionalization (Part I). Asian Academic Reseach Journal an Social Science and Humanities, 2(8) 246-282.

[22] Aparicio, M. (2015 b). The Theory of the Three-Dimensional Spiral of Sense: An Application with special Reference to Identity and Professionalization in other Disciplinary Areas (Part 2). Asian Academic Research Journal of Social Sciences \& Humanities, 2(8), 194-245.

[23] Aparicio, M. \& Cros, F. (2015 c). Trajectoires et identités. Un avenir incertain pour les docteurs? Paris: L'Harmattan.

[24] Aparicio, M. (2016 a). Professionalization and Identity. A Study in Relation to Achievement at University at the Light of a New Paradigm: The Spiral Three Dimensional of Sens. European Journal of Interdisciplinary Studies, 1(3), 126-131. 
[25] Aparicio, M. (2016 b). Professionalization, Insertion, Mobility and Professional Status. A Comparative Analysis in Populations of Doctors. European Journal of Social Sciences, Educational and Research, 8(1).

[26] Aparicio, M. (2016 c). Professional Mobility and "Objective" and "Subjective" Satisfaction. A Non-Linear Analysis from The Theory of The Three-Dimensional Spiral of Sense in Population of Doctors. European Journal of Interdisciplinary Studies. 3(1), 52-62.

[27] Aparicio, M. (2016 d). Doctoral Education: An Academic and Labor Market "Plus"? International Educational Scientific Research Journal, 2(10), 123-127.

[28] Aparicio, M. (2016 e). The Three Dimensional Spiral of Sense: Training for Cultural / Institutional Autonomy or Homogenization? A Study in the Light of the "Agenda-Setting" Theory and a New Paradigm. Journal of USCHINA Education Review, 6(9), 554-560.

[29] Aparicio, M. (2016 f). Satisfaction and Professional Mobility. A French Argentine Study about PhD, in the Light of a Sui Generis Paradigm. Sociology Study, 6(7), Serial Number 62, 470-477.

[30] Aparicio, M. (2016 g). The Identity and Pathways of Argentine Undergraduates. Research Contributions to Improvements in Quality. International Journal of Humanities and Social Sciences, 6(10), 20-30.

[31] Aparicio, M. (2019). Resiliency and Cooperation or Regarding Social and Collective Competencies for University Achievement. An Analysis from a Systemic Perspective. European Journal of Social Sciences Education and Research, 5(3), 123-135.

[32] Argyris, C. (1982). Learning and Action: Individual and Organizational. San Francisco: Jossey-Bass. Cit. par Shön, op. cit.

[33] Bandura, A. (1977). Self-Efficacy. Toward an Unifying Theory of Behavioral Change, Psychological Review, 34(2), 191-215.

[34] Bateson, G., Jackson, D.-D ; Haley, J. \& Wealand, J. (1956), « Towards a theory of Schizophrenia », Behavioral Scientist, N ${ }^{\circ}$ 1, 251-266.

[35] Bateson, Bridwistell, Goffman, Hall, Jackson, Scheflen, Sigman \& Watzlawick (1984). La nouvelle communication. Paris: Seuil.

[36] Berlinger, L. (2017). Ré-invenver l'école. Paris: Fabert.

[37] Csikzentmihalyi, M. (1988). Society, Culture and Person: A System View of Creativity. In R.J. Stemberg (Ed.), The nature of Creativity : Contemporany Psychological Perspectives (325-339). Cambridge University Press.

[38] Csikzentmihalyi, M. (1998). Creatividad. El fluir y la psicología del descubrimiento de la invención. Paris I Barcelona (1a ed. 1978).

[39] Crozier, M. (1963). Le phénomène bureaucratique. Paris: Le Seuil.

[40] Crozier, M. \& Friedberg, E. (1977). L'acteur et le système. Paris: Le Seuil.

[41] Donnadieu, G., 2008, La communication inter-humaine. In N. Kridis, op cit, 2008, 49-73.

[42] Dubar, C. (1991). Formation continue et dynamique des identités professionnelles. Formation et Emploi, 34, 87-100.

[43] Dubar, C. (2000a). La socialisation. Paris: Colin.

[44] Dubar, C. (2000b). La crise des identités. Paris: PUF.

[45] Gilbert, P. (2011). La gestion prévisionnelle des ressources humaines. La Découverte, $2^{e}$ éd.

[46] Gilbert, P. \& Chiapello, E. (2013) Sociologie des outils de gestion. Paris : La Découverte.

[47] Kaddouri, M. et al. (2008). La question identitaire dans le travail et la formation. Paris: L'Harmattan.

[48] Kridis, N. (2008). Communication et innovation. Paris : L'Harmattan.

[49] McClelland, D. (1961). The Achieving Society (1961). California University: Van Nostrand.

[50] Mauss, M. (1923). Essai sur le don. Paris: PUF (ré édition, 1950).

[51] Malinvaud, E. (1996). Pourquoi les économistes ne font pas de découvertes, Revue d'économie politique, 6 (116), novembre-décembre, 929-942.

[52] Masmoudi, S. (2008). Processus Innovateur au sein des Sciences cognitives. In N. Kridis, op. cit., 29-47.

[53] Moscovici, S., 1961. La psychanalyse, son image et son public. Paris : PUF.

[54] Neisser, J.F (1985). Cognitive Psychology. New York: Appleton Centuy Crofts.

[55] OECD. (2018 a)PISA. http://www.oecd.org/pisa/pisaenespaol.htm/consultado 2 mai 2018. Cit by Aparicio, 2019, op.cit.

[56] OECD (2018 b). World Economic Forum "Futur of job report". https://www.infobae.com/educacion/2018/01/14/cualesson- 
[57] los-paises-que-mejor-se-preparan-para-el-trabajo-del-futuro/ Consulting May 2th 2018. Cit by Aparicio, 2019, op.cit.

[58] Perrenoud, Ph. (2007). Diez nuevas competencias para enseñar. Barcelona: Ed. Graó (5a ed.).

[59] PICTO 2016-2019-0008. Agence nationale de science, technologie et innovation, Argentine. Projet dirigé par M. Aparicio, intitulé "Trayectorias laborales, Satisfacción, Profesionalización e Identidad. Un estudio en la UNCuyo en distintos contextos organizacionales (científicos, docentes y administrativos)".

[60] Popper, K. (1984). In Search of a Better World: Lectures and Essays from Thirty Years. Paperback, 256 pages, November 30th 1995 by Routledge.

[61] Shön, D. (1983). The Reflexive Practitioner. New York: Basic Books.

[62] Schumpeter, J. (2015). Capitalismo, socialismo y democracia.Barcelona: Página Indómita, $1^{2 a}$ ed., 1942.

[63] Silva, A. M. \& Aparicio, M. (Eds.) (2015 b). International Handbook about Professional Identities. New York: Academic and Scientific Publishing.

[64] UNESCO (1982).Declaración de México. Conferencia Mundial de las Políticas Culturales.

[65] Watzlawick, P. (1980). Le langage du changement.Paris : Seuil. 